\title{
Removal of Fluoride from Water Using Mesoporous MCM-41: An Optimization Approach Using Response Surface Methodology (RSM)
}

\section{Bodhaditya Das ${ }^{1}$, Saumen Banerjee ${ }^{2 *}$, Prasanta K. Raul ${ }^{1 *}$, Rashmi R. Devi' ${ }^{1}$ Iohbor M. Umlong1, Anup K. Talukdar ${ }^{3}$, Sanjai K. Dwivedi ${ }^{1}$}

${ }^{1}$ Defence Research Laboratory, Tezpur, Assam, India

${ }^{2}$ Defence Materials and Stores Research and Development Establishment, Kanpur, UP, India

${ }^{3}$ Department of Chemistry, Gauhati University, Assam, India

Email: *saumenbanerjee2004@gmail.com, * prasanta.drdo@gmail.com

How to cite this paper: Das, B., Banerjee, S., Raul, P.K., Devi, R.R., Umlong, I.M., Talukdar, A.K. and Dwivedi, S.K. (2021) Removal of Fluoride from Water Using Mesoporous MCM-41: An Optimization Approach Using Response Surface Methodology (RSM). Advances in Nanoparticles, $10,95-114$

https://doi.org/10.4236/anp.2021.103007

Received: May 21, 2021

Accepted: August 1, 2021

Published: August 4, 2021

Copyright $\odot 2021$ by author(s) and Scientific Research Publishing Inc. This work is licensed under the Creative Commons Attribution International License (CC BY 4.0).

http://creativecommons.org/licenses/by/4.0/

\begin{abstract}
Fluoride above $1.5 \mathrm{mg} \cdot \mathrm{L}^{-1}$ is injurious to health. Removal of fluoride from water using mesoporous MCM-41 as a strong adsorbent material has been attempted. Characterization using transmission electron microscopic study of calcined MCM-41 showed the regular hexagonal array of mesoporous channels with an average size of $20 \mathrm{~nm}$ and the surface area (BET study) of $1306.96 \mathrm{~m}^{2} \cdot \mathrm{g}^{-1}$. The average pore size of the particles was found to be 14.21 $\mathrm{nm}$. A study on the effect of contact time on the removal of fluoride revealed that more than $85 \%$ uptake of fluoride onto MCM- 41 was achieved at a contact time of $120 \mathrm{~min}$. From the Langmuir adsorption study, the maximum sorption capacity of fluoride was found to be $63.05 \mathrm{mg} / \mathrm{g}$ at $301 \mathrm{~K}$. From the thermodynamic study, the $+\Delta \mathrm{H}^{\circ}$ value of $2.29 \mathrm{~kJ} \cdot \mathrm{mol}^{-1}$ indicated the endothermic nature of the removal process. Application of Response Surface Model suggested that $77.88 \%$ of fluoride removal can be achieved at fluoride concentration of $10 \mathrm{mg} \cdot \mathrm{L}^{-1}, \mathrm{pH}(6.3)$, and contact time of $120 \mathrm{~min}$.
\end{abstract}

\section{Keywords}

MCM-41, Mesoporous Silica, Adsorption, Fluoride, Response Surface Methodology (RSM)

\section{Introduction}

Chronic Fluoride toxicity is caused mainly due to prolonged consumption of 
excess fluoride concentration through drinking water. Fluorosis is prevalent in India amongst the 23 nations in the world. 19 states of India are affected with various forms of fluorosis revealed from various reports. It is reported that the prevalence of dental and non-skeletal fluorosis is significantly at a higher rate [1]. Near about 62 million people are affected by fluorosis in India concluded to various survey reports. Fluoride in drinking water is known for both beneficial and detrimental health effects. As the guideline of the World Health Organization (WHO), the maximum permissible level of fluoride in drinking water is 1.5 $\mathrm{mg} \cdot \mathrm{L}^{-1}$ [2]. The many pockets of Assam region of North Eastern India have a high concentration of fluoride in drinking water where cases of endemic fluorosis are reported [3]. Amid the negative impact of fluoride on human health, researches have been prompted to study the removal of high concentration fluoride from drinking water.

In the recent decay, the application of nanoscience and nanotechnology is emerging in a new dimension, so, researchers have explored the unusual and unique properties of nanomaterials for environmental remediation [4] [5]. In this regard, mesoporous materials are attractive in the domain which proved their affinity in absorbing a range of organic and inorganic materials. In 1991, a class of new ordered mesostructured materials called M41S (viz. MCM-41, MCM-48 and MCM-50) were discovered [6] [7]. The morphology and pore size of these materials can be tailored through simple manipulation of the synthetic conditions. Si-based MCM-41 has unique properties viz. ordered pore structure with unimodal pore size distributions, large surface area, due to which its application is very significant as catalysts, in adsorption and separation processes [8] [9]. In recent years, it has been widely studied the application of mesoporous materials for the removal of anionic contaminants from water by the adsorption process [10]. But very few reports are available for defluoridation process from drinking water using mesoporous materials.

In the present study, it was attempted to prepare an appropriate mesoporous adsorbent to monitor the adsorption behavior of fluoride from contaminated water and to study the efficacy of the adsorbent. The method of synthesis was slightly modified than the classical one in order to minimize the time as well as the use of reagents [11]. It has also been described the adsorption by variation of parameters such as initial concentration, contact time, and $\mathrm{pH}$ effect. The isotherms, kinetics model, and thermodynamic processes were also taken up in the study to understand the mechanism of adsorption. Further, a Box-Behnken factorial design was used to optimize the removal conditions by MCM- 41 with a view to predicting the fluoride removal efficiency through adsorption.

\section{Materials and Methods}

\subsection{Materials}

The required chemicals such as tetraethylorthosilicate (TEOS), cetyltrimethylammonium bromide (CTAB), ammonia solution (30\%), hydrochloric acid, so- 
dium hydroxide and sodium fluoride (Merck, India) were of analytical grade and used without further purification.

\subsection{Synthesis of MCM-41}

As the reported procedure [12] Mesoporous MCM-41 was synthesized with slight modification. The reactant-compositions were maintained at the following molar composition of nCTAB:TEOS:NH3 $=0.023: 0.043: 2.470$ as previously optimized. A mixture of $\mathrm{CTAB}$ and ammonia solution (30\%) was stirred continuously using a laboratory stirrer until a clear homogenous solution was obtained. Then a required amount of TEOS was added drop-wise into the above mixture with the help of a pressure-equalizing funnel. The mixture was further stirred for $90 \mathrm{~min}$ at room temperature till a white precipitate is formed. The obtained product was then filtered and washed properly with distilled water. Finally, the solid product was heated at $70^{\circ} \mathrm{C}$ in a vacuum oven in the absence of air and cooled to normal temperature followed by calcination at $560^{\circ} \mathrm{C}$ for $6 \mathrm{~h}$. The final product so obtained was used for the adsorption studies.

\subsection{Characterization of the Sorbent}

Phase analysis of mesoporous MCM-41 was carried out by a powder X-ray diffractometer (Bruker D8). The measurement conditions were taken as follows:

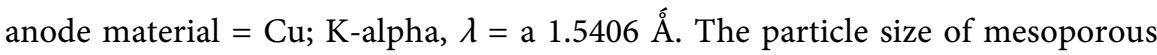
MCM-41 was measured using a transmission electron microscope (TEM, JEOL JEM 2100) at an acceleration voltage of $200 \mathrm{kv}$ and digital images were taken with a charge coupled device (CCD) camera. Energy dispersive X-ray (EDX) analysis of samples was carried out with an instrument JEOL 6390LV attached to the scanning electron microscope (SEM). A BET surface area analyzer (Micromeritics Tristar 3000) was used to measure nitrogen adsorption isotherm at 77 $\mathrm{K}$. The thermogravimetric analysis (TGA) was carried out using TGA instrument (Metler Toledo stac system).

\subsection{Adsorption Experiments}

The sorption isotherm and kinetic experiments were carried out by batch equilibrium method. The batch adsorption experiments were carried out by mixing known weight of the adsorbent material with $100 \mathrm{~mL}$ of working standard solution, placed in a $250 \mathrm{~mL}$ conical flask. The contents in the flask were shaken thoroughly for $2 \mathrm{~h}$ on a mechanical shaker (IKA 400 ic control) with a speed of $165 \pm 2 \mathrm{rpm}$. The solution was centrifuged and the mother liquor was analyzed for residual contaminant concentration using an ion analyzer (Orion, Thermo Scientific Ltd.) equipped with fluoride selective combined electrode. All adsorption isotherm experiments were conducted at a temperature $\left(28^{\circ} \mathrm{C} \pm 0.1^{\circ} \mathrm{C}\right)$. Batch adsorption experiments were conducted to investigate the effect of various parameters such as initial concentration, $\mathrm{pH}$ effect, contact time, etc.

The specific amount of contaminant adsorbed was calculated by the following 
formula

$$
Q_{e}=\left(C_{0}-C_{e}\right) \times V / W
$$

where $Q_{e}$ is the adsorption capacity $\left(\mathrm{mg} \cdot \mathrm{g}^{-1}\right)$ of the solid at equilibrium; $C_{0}$ and $C_{e}$ are the initial and equilibrium concentration of contaminant $\left(\mathrm{mg} \cdot \mathrm{L}^{-1}\right)$ respectively; $V$ is the volume of the aqueous solution; $W$ is the mass $(\mathrm{g})$ of adsorbent used in the experiments [13]. A pH meter (Model: Sartorius PT-10) was used to measure $\mathrm{pH}$. The kinetic and thermodynamic parameters of the adsorption were established by conducting the experiments at three different temperatures 301, 306 and $311 \mathrm{~K}$ in a controlled mechanical shaker.

\subsection{Response Surface Methodology (RSM)}

The Box-Behnken factorial design (BBD) was used to optimize the fluoride removal conditions by MCM-41. The detailed techniques of Response Surface Methodology (RSM) as a statistical tool are given in the results and discussion sections. The Box-Behnken factorial design was used to optimize the fluoride removal conditions by MCM-41. The Box-Behnken factorial design was used to optimize the fluoride removal conditions by MCM-41. Since different variables are usually expressed in different units and/or have different limits of variation, the significance of their effects on response can only be compared after they are coded. For statistical calculations, the variable $X_{i}$ was coded as $X_{i}$ according to the following equation

$$
x_{i}=\frac{X_{i}-X_{o}}{\Delta X_{i}}
$$

where $X_{i}$ is the real value of the $t$ th independent variable, $X_{o}$ is the real value of an independent variable at the centre point and $\Delta X_{i}$ is the step change. $\mathrm{pH}\left(X_{1}\right)$, Initial concentration $\left(X_{2}\right)$ and contact time $\left(X_{3}\right)$ were chosen as the independent variables during the removal process. The range and levels were listed in Table 1. The removal efficiency for fluoride was selected as the dependent variable. The response variable was fitted by a second-order model in the form of quadratic polynomial equation

$$
y=a_{0}+\sum_{i=1}^{n} a_{i} x_{i}+\sum_{i=1}^{n} a_{i i} x_{i}^{2}+\sum_{i=1}^{n} \sum_{j=1}^{n} a_{i j} x_{i} x_{j}, i<j
$$

where, is the response variable to be modelled; $a_{0}, a_{i j} a_{i i}$ and $a_{i j}$ are constant regression coefficients of the model; $\mathrm{x}_{i}$ and $\mathrm{x}_{j}(i=1 \rightarrow 4 ; j=1 \rightarrow 4 ; i \neq j)$ represent the independent variables in the form of coded values. The actual design of this work was presented in Table 2. Based on this table, the experiments were conducted for obtaining the response, i.e. removal efficiency for fluoride; at the corresponding independent variables addressed in the experimental design matrix by applying a quadratic model. The parameters of the response equations and corresponding analysis on variables were evaluated using Minitab16. The significance of quadratic regression model was also evaluated using the analysis of variance (ANOVA). Experimented and theoretical values are reflected in Table 2. 
Table 1. Experimental ranges and levels of the independent variables.

\begin{tabular}{cccc}
\hline Variables & \multicolumn{2}{c}{ Range and levels } \\
\hline & -1 & 0 & +1 \\
$X_{1}, \mathrm{pH}$ & 3 & 6 & 9 \\
$X_{2}$, Initial concentration & 5 & 10 & 15 \\
$X_{3}$, Contact time & 20 & 120 & 220 \\
\hline
\end{tabular}

Table 2. BBD and results for the study of four experimental results.

\begin{tabular}{cccccc}
\hline & \multicolumn{3}{c}{ Variable (coded) } & \multicolumn{2}{c}{ \% Removal of fluoride } \\
\hline Run & $X_{1}$ & $X_{2}$ & $X_{3}$ & Experimental & Predicted \\
\hline 1 & -1 & -1 & 0 & 45.5 & 46.487 \\
2 & 1 & -1 & 0 & 35.5 & 38.262 \\
3 & -1 & 1 & 0 & 23.8 & 20.037 \\
4 & 1 & 1 & 0 & 37.4 & 35.412 \\
5 & -1 & 0 & -1 & 10.5 & 10.750 \\
6 & 1 & 0 & -1 & 14.9 & 13.375 \\
7 & -1 & 0 & 1 & 17.5 & 19.025 \\
8 & 1 & 0 & 1 & 23.8 & 23.550 \\
9 & 0 & -1 & -1 & 80.5 & 78.2625 \\
10 & 0 & 1 & -1 & 58.8 & 63.312 \\
11 & 0 & -1 & 1 & 86.7 & 87.187 \\
12 & 0 & 1 & 1 & 70.6 & 72.837 \\
13 & 0 & 0 & 0 & 77.5 & 78.166 \\
14 & 0 & 0 & 0 & 78.0 & 78.166 \\
15 & 0 & 0 & 0 & 79.0 &
\end{tabular}

\section{Result and Discussions}

\subsection{Characterization}

The X-ray powder diffraction patterns of calcined MCM-41 are reflected in Figure 1. The diffraction lines are (100), (110) and (200), indexing the hexagonal regularity of MCM-41 as per literature of XRD pattern [14]. The X-ray diffractrograms of MCM-41 after calcination in air at $560^{\circ} \mathrm{C}$ for $6 \mathrm{~h}$, contain a sharp and main the d100 diffracting planes is observed at 2 value of $2.45^{\circ}$ followed by other two very weaker signals. The large band is due to the contribution of the amorphous silica walls [15]. The BET surface area of MCM-41 was found to be $1306.90 \mathrm{~m}^{2} \cdot \mathrm{g}^{-1}$, whereas the total pore volume was $0.5507 \mathrm{~cm}^{3} \cdot \mathrm{g}^{-1}$. TEM micrograph of MCM-41 powder showing uniform distribution of the particles followed by the particle size $>20 \mathrm{~nm}$ was presented in Figure 2. The interlayer spacing was found to be $4.1 \mathrm{~nm}$, as depicted in Figure 2 (onset). 


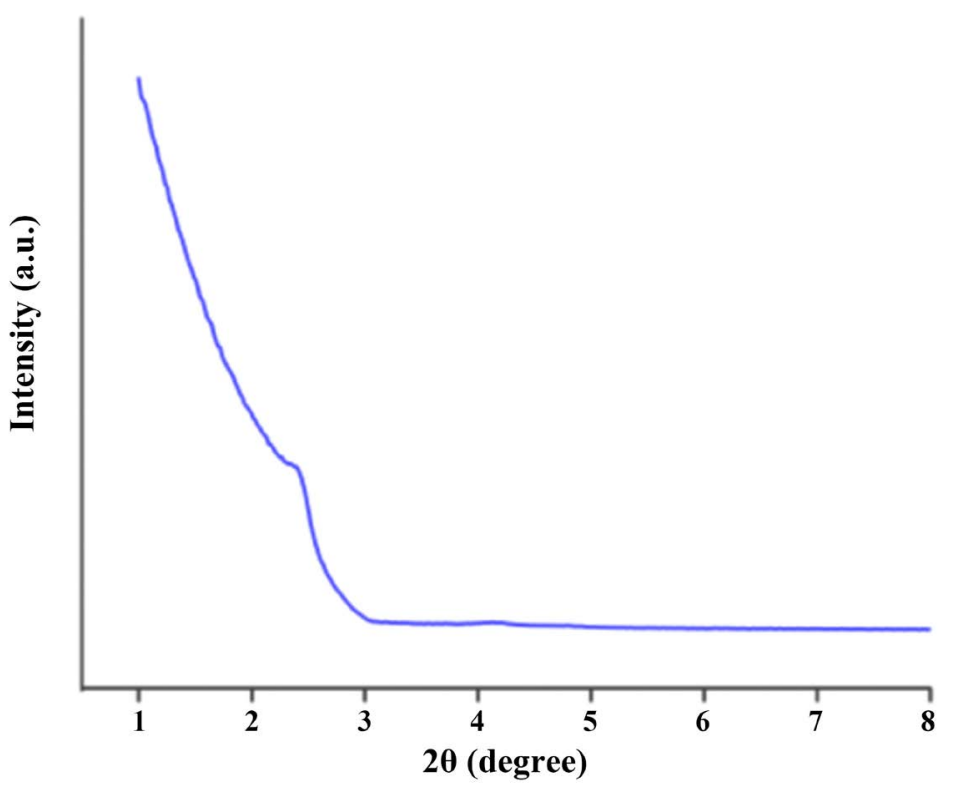

Figure 1. XRD patterns of (a) calcined MCM-41.

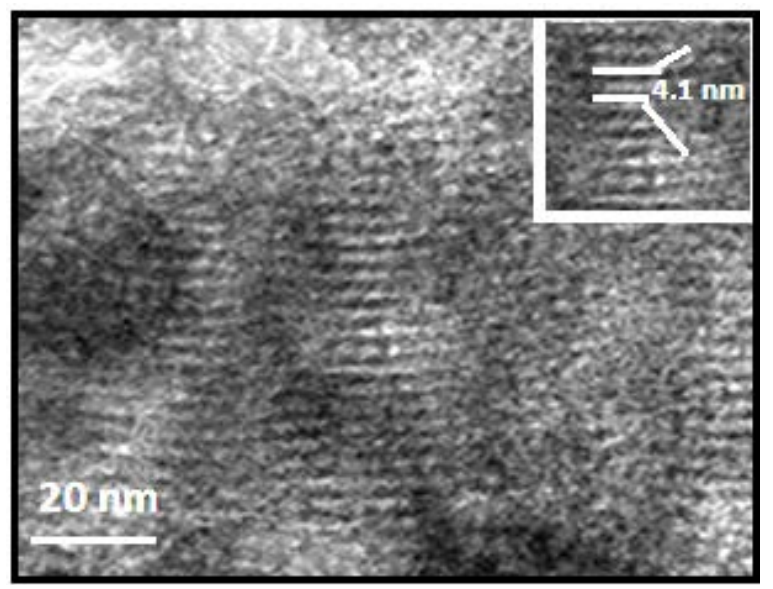

Figure 2. TEM image of MCM-41.

\subsection{Isotherm of Nitrogen-Adsorption-Desorption}

The low-temperature nitrogen adsorption-desorption isotherm and pore size distribution patterns of mesoporous MCM-41 are depicted in Figure 3. At a relative pressure $\mathrm{P} / \mathrm{P} 0 \sim 0.42$, a sharp increase in the adsorbed and desorbed volumes is reflected; indicates the uniformity of the pore size distribution, and corresponds to capillary condensation in the mesopores [16]. The TGA curve of MCM-41 showed three-step profile of weight loss in the temperature range 313 $413 \mathrm{~K}, 413-530 \mathrm{~K}$ and $653-1023 \mathrm{~K}$. Figure 4 depicts the TGA thermogram. The TGA curve of MCM-41 showed three-step profile of weight loss in the temperature range $313-413 \mathrm{~K}, 413-530 \mathrm{~K}$ and $653-1023 \mathrm{~K}$. The initial small weight loss around the range of $313-413 \mathrm{~K}$ is due to the desorption of physically adsorbed water. Removal of organic surfactants is completed in two steps. Similar observations were reported for the synthesis of different mesoporous materials 


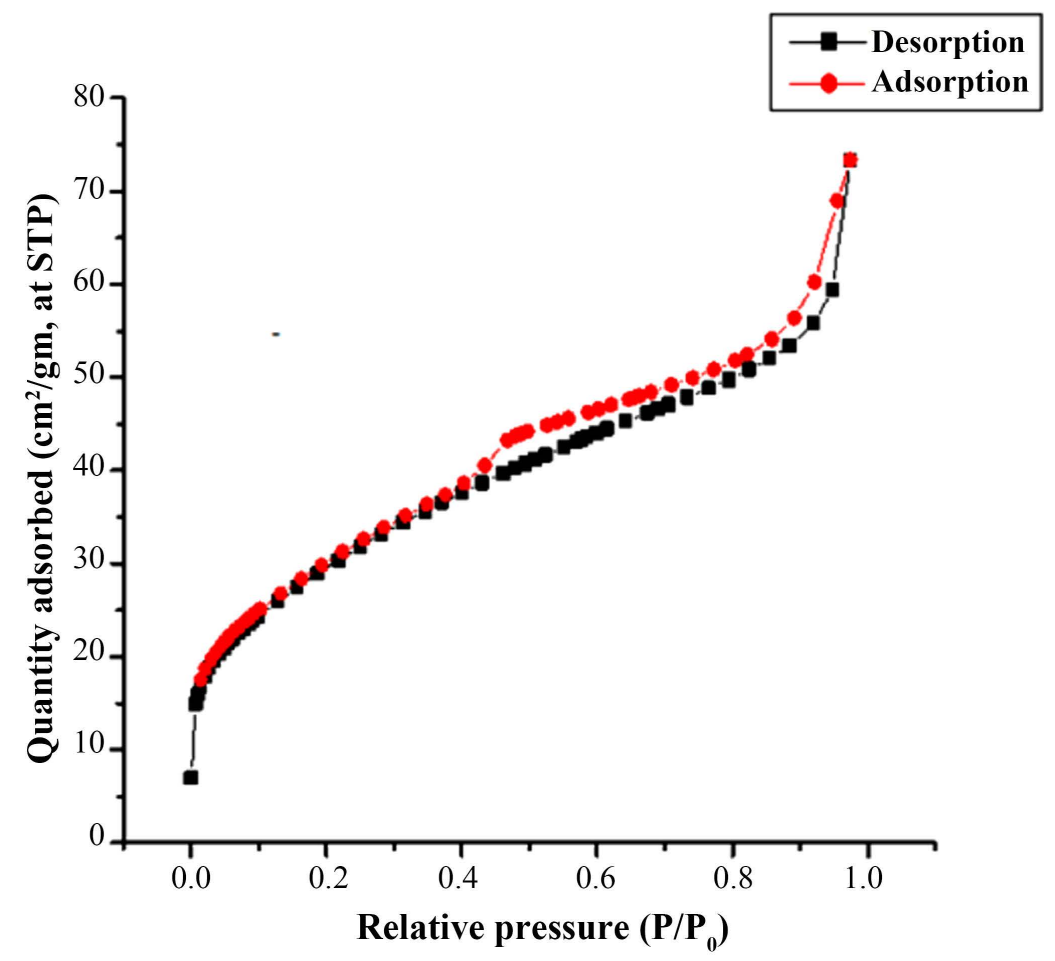

Figure 3. $\mathrm{N}_{2}$ adsorption-desorption isotherm.

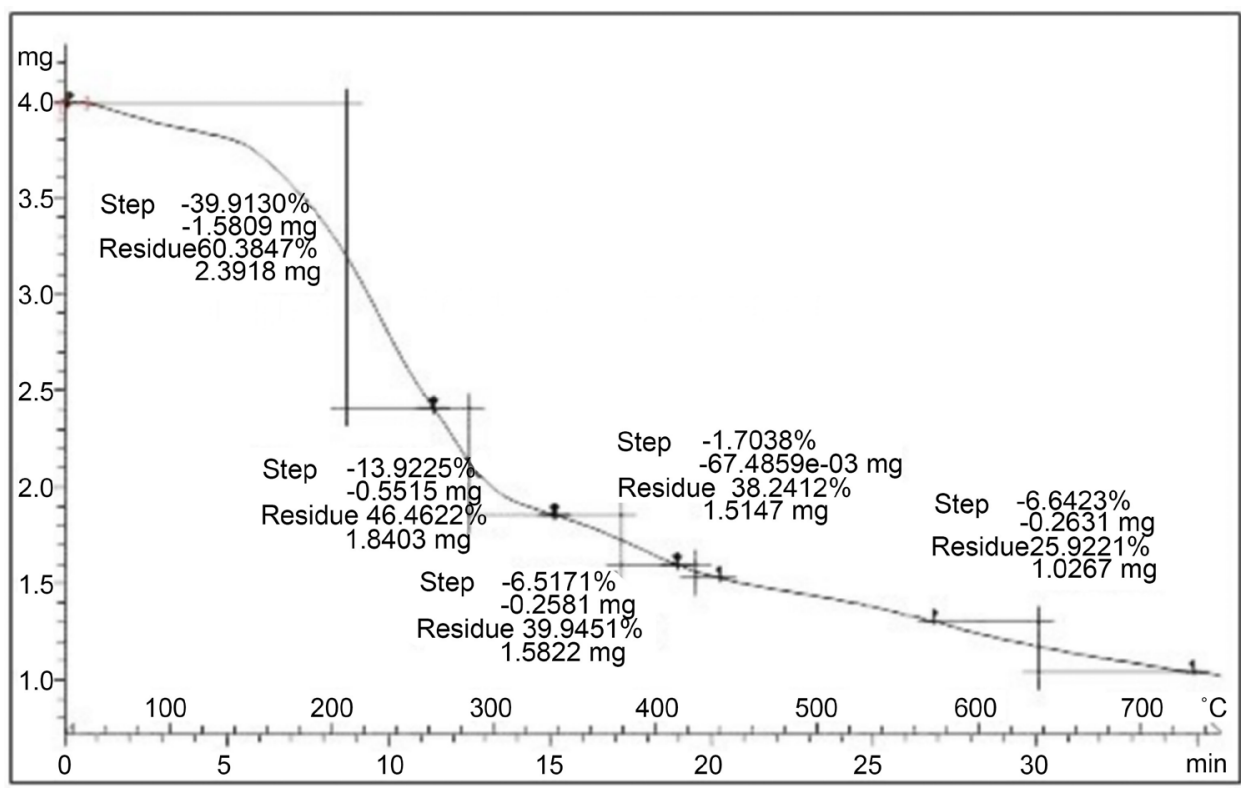

Figure 4. TGA of MCM-41.

prepared by microemulsion method using heptanes-water-CTAB system [17] Low-temperature $\mathrm{N}_{2}$ adsorption isotherms give the most reliable information about the porous structure of solids. Figure 5(a) and Figure 5(b) shows the SEM images of surface morphology of mesoporous MCM-41 and after adsorption of fluoride respectively. The elemental analysis of MCM-41 before and after fluoride adsorption is further shown in Figure 6(a) and Figure 6(b). 


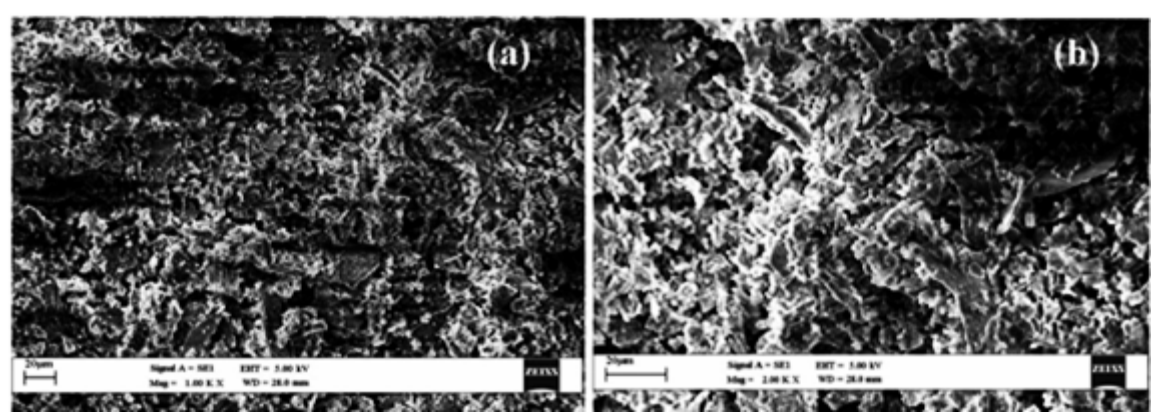

Figure 5. SEM image of MCM-41 (a) before adsorption and (b) after fluoride adsorption.
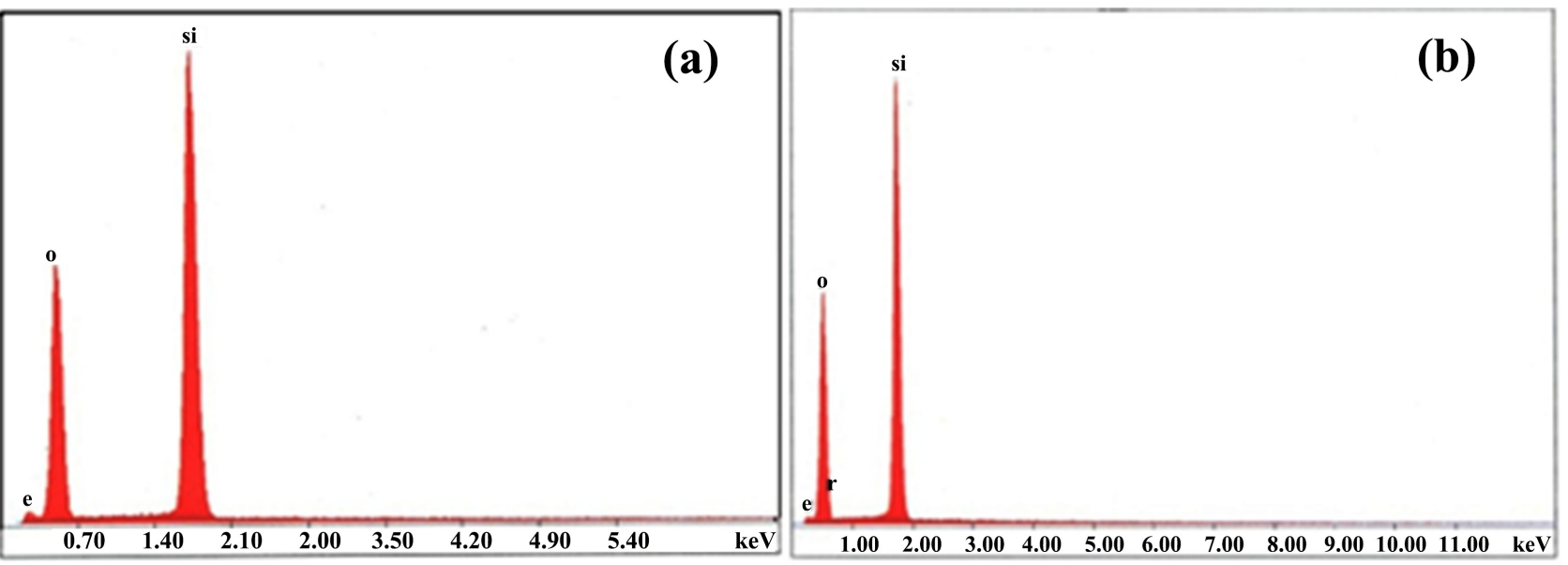

Figure 6. EDX analysis of MCM-41 (a) Before fluoride adsorption; (b) After fluoride adsorption.

\subsection{Adsorption of Fluoride}

\subsubsection{Effect of the Initial Concentration of Adsorbate}

$75 \%$ removal of fluoride was observed taking initial concentration $10 \mathrm{mg} \cdot \mathrm{L}^{-1}$ and adsorbent dose of $1 \mathrm{mg} \cdot \mathrm{L}^{-1}$ within $2 \mathrm{~h}$ of contact time. When the concentration of fluoride is increased, the competition for the active adsorption sites also increased and the adsorption process was gradually declined [18]. The findings are displayed in Figure 7.

\subsubsection{Determination of Zero Point Charge (ZPC)}

The surface charge of the materials is usually determined by the Zero Point Charge (ZPC). The adsorption of the specific adsorbate on adsorbent depends on the surface charge of the adsorbent. Figure 8 depicts the $\mathrm{pH}$ of the solution after adsorption $v s \mathrm{pH}$ before adsorption [19]. The horizontal portion of the graph parallel to the $\mathrm{X}$-axis indicates the ZPC of the material. The ZPC value of mesoporous MCM-41 is found to be 2.8 [20]. From that, it was concluded that the adsorbent surface had a positive charge (cationic) in aqueous medium.

\subsubsection{Sorption Mechanism and pH Effect}

The $\mathrm{pH}$ of the aqueous solution plays an important role which controls the adsorption at the water adsorbent interface [21]. Therefore, the adsorption of fluoride on MCM-41 was examined at different $\mathrm{pH}$ from 1.5 to 10.5 keeping other 


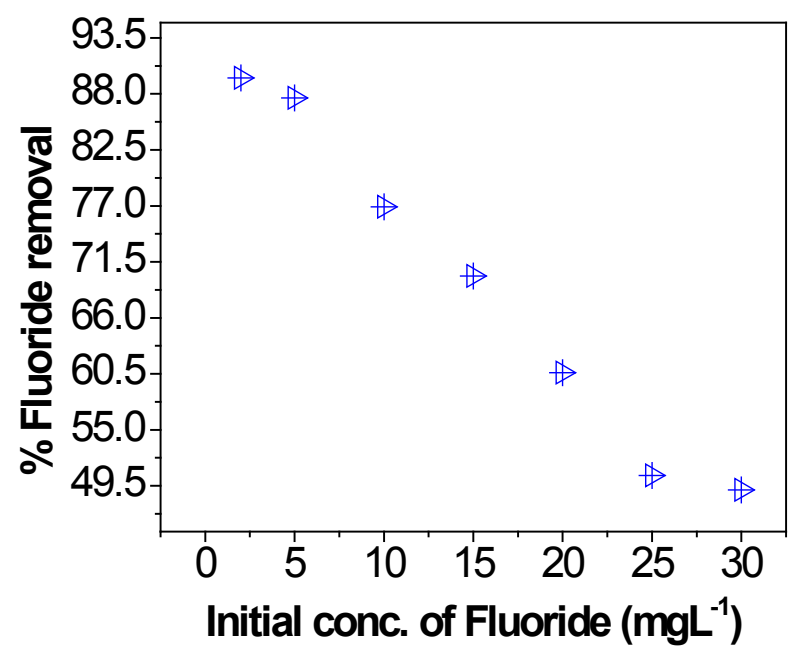

Figure 7. Effect of initial concentration of Fluoride on removal of fluoride.

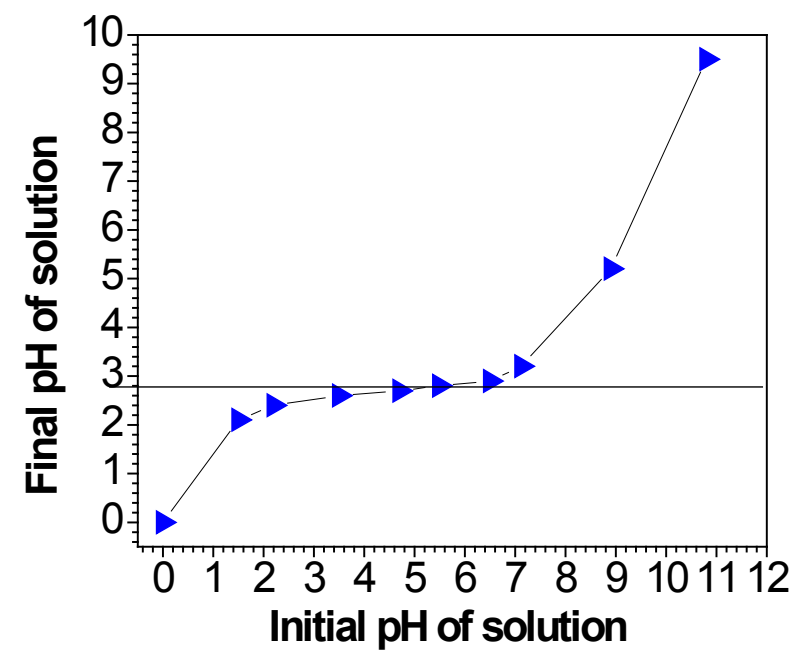

Figure 8. Plot of final $\mathrm{pH}$ with initial $\mathrm{pH}$ of fluoride solution.

parameters constant as shown in Figure 9. The percentage of fluoride removal was found to be more than $50 \%$ at acidic $\mathrm{pH}$, whereas it was less than $40 \%$ at basic $\mathrm{pH}$. At $301 \mathrm{~K}$ the maximum sorption capacity was found to be $63.05 \mathrm{mg} \cdot \mathrm{g}^{-1}$ for fluoride and at $\mathrm{pH} 6.3$ (Figure 9). The following reactions are considered to understand the fluoride adsorption behaviour under various $\mathrm{pH}$ values [22] [23],

$$
\begin{gathered}
\mathrm{HF} \leftrightarrow \mathrm{H}^{+}+\mathrm{F}^{-} \\
\equiv \mathrm{SOH}+\mathrm{H}^{+} \leftrightarrow \equiv \mathrm{SOH}_{2}^{+} \\
\equiv \mathrm{SOH}+\mathrm{OH}^{-} \leftrightarrow \equiv \mathrm{SO}^{-}+\mathrm{H}_{2} \mathrm{O} \\
\equiv \mathrm{SOH}_{2}^{+}+\mathrm{F}^{-} \leftrightarrow \equiv \mathrm{SF}+\mathrm{H}_{2} \mathrm{O} \\
\equiv \mathrm{SOH}+\mathrm{F}^{-} \leftrightarrow \equiv \mathrm{SO}^{-}+\mathrm{OH}^{-}
\end{gathered}
$$

The overall reaction can be written as

$$
\equiv \mathrm{SOH}+\mathrm{H}^{+}+\mathrm{F}^{-} \leftrightarrow \equiv \mathrm{SF}+\mathrm{H}_{2},
$$




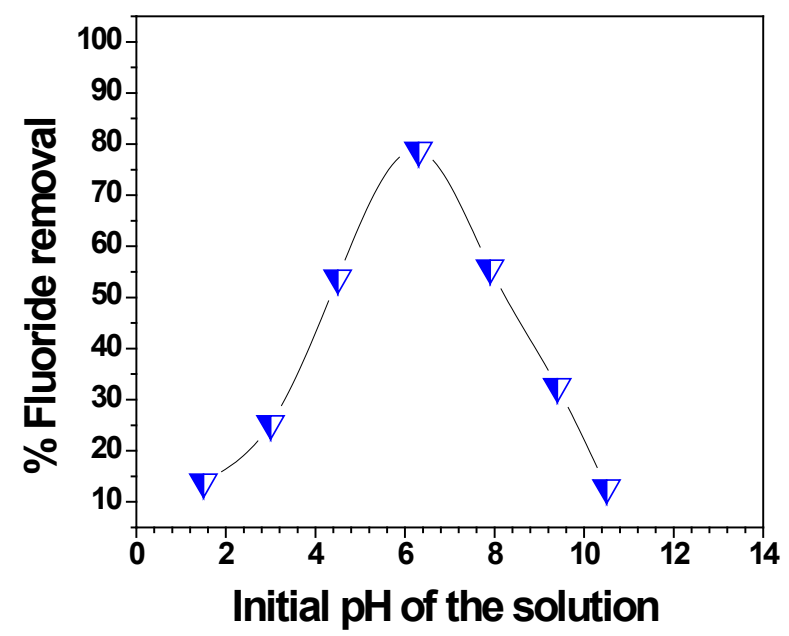

Figure 9. Effect of $\mathrm{pH}$ on adsorption.

where $\equiv \mathrm{SOH}, \equiv \mathrm{SOH}_{2}^{+}$and $\equiv \mathrm{SO}^{-}$are the neutral, protonated and deprotonated sites on MCM-41 respectively and $\equiv \mathrm{SF}$, active site fluoride complex. Equation (3) reflects the ionization of $\mathrm{HF}$ in solution at low $\mathrm{pH}$. At low $\mathrm{pH}$ values, HF is weakly ionized $(\mathrm{pKa}=3.2)$ in solution, in that case, fluoride uptake capacity is reduced when $\mathrm{pH}$ is very less than 6.0 , since a fraction of fluoride becomes unavailable for adsorption process. When the adsorption system (fluoride solution/MCM-41) was operated at $7>\mathrm{pH}>6.0$, the reaction site becomes protonated according to Equation 4 as there was so much proton available in the acidic medium leading to the enhancement of fluoride adsorption (Equation (3)) compared to fluoride adsorption at neutral $\mathrm{pH}$ (Equation (7)). The fluoride adsorption decreased sharply at $\mathrm{pH}>7.29$ due to the increased repulsive forces between the negatively charged fluoride ions and the $\mathrm{SO}^{-}$(Equation (6)). It may be concluded that the mechanism of fluoride removal on MCM-41 follows both adsorption and ion-exchange mechanism [24].

\subsubsection{Effect of Contact Time}

The rapid adsorption of fluoride took place within $90 \mathrm{~min}$ is depicted in Figure 10. After that adsorption becomes slow and almost reached equilibrium within $120 \mathrm{~min}$. When the contact time is increased up to $8 \mathrm{~h}$, no further appreciable adsorption took place (less than 1\%) indicating that complete adsorption [25] occurred within $2 \mathrm{~h}$. Thus, all the adsorption experiments were conducted for $2 \mathrm{~h}$.

\subsubsection{Adsorption Isotherm}

\section{Langmuir isotherm}

For estimation of maximum fluoride uptake $\left(q_{m}\right)$ at different fluoride concentrations $\left(2-25 \mathrm{mg} \cdot \mathrm{L}^{-1}\right)$ the Langmuir sorption model was adopted. The Langmuir isotherm [26] is expressed as

$$
\frac{1}{q_{e}}=\frac{1}{q_{m}} \frac{1}{b} \frac{1}{C_{e}}+\frac{1}{q_{m}}
$$




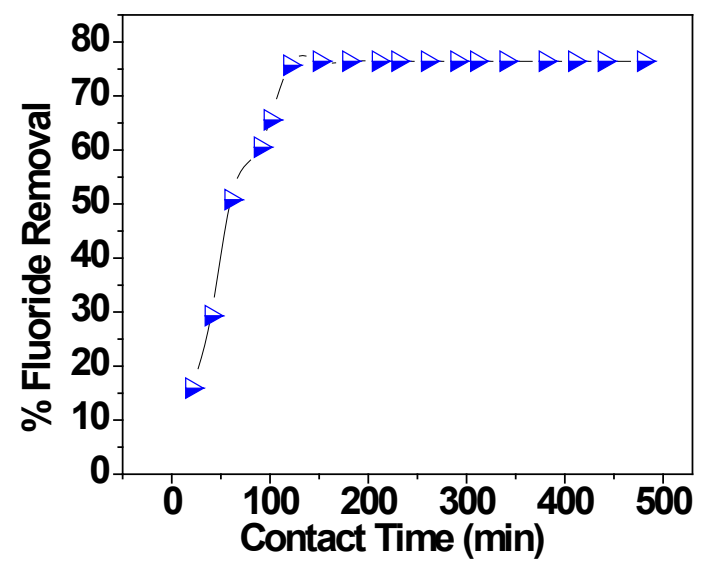

Figure 10. Effect of contact time.

where $q_{e}$ is the equilibrium quantity adsorbed $\left(\mathrm{mg} \cdot \mathrm{g}^{-1}\right), C_{e}$ is the equilibrium concentration $\left(\mathrm{mg} \cdot \mathrm{L}^{-1}\right), q_{m}$ is the maximum adsorption capacity $\left(\mathrm{mg} \cdot \mathrm{g}^{-1}\right)$ and $b$ is the Langmuir constant. The linear plot of $\frac{1}{C_{e}}$ vs $\frac{1}{q_{e}}$ (Figure 11(a)) with higher $R^{2}$ value indicates the monolayer adsorption on mesoporous MCM-41. The values of $q_{m}$ and $b$ were calculated from the slope and intercept respectively are presented in Table 3.

Freundlich isotherm

The linear form of the Freundlich isotherm [27] equation is expressed as

$$
\ln q_{e}=\ln k_{f}+\frac{1}{n} \ln C_{e}
$$

where $q_{e}$ is the adsorbed amount $\left(\mathrm{mg} \cdot \mathrm{g}^{-1}\right), C_{e}$ is the equilibrium fluoride concentration $\left(\mathrm{mg} \cdot \mathrm{L}^{-1}\right), k_{f}\left(\mathrm{mg} \cdot \mathrm{g}^{-1}\right)$ is the Freundlich constant related to adsorption capacity and $n$ is the constant related to energy of intensity of adsorption. The value of $k_{f}$ and $n$ (Table 3) are obtained from the linear plot of $\ln q_{e}$ vs $\ln C_{e}$ (Figure 11(b)). $n$ values lying between 1 and 10 also indicate the favourable conditions for adsorption isotherms as well. From the adsorption studies, it is found that the Langmuir adsorption model is better fitted than Freundlich one. It was also supported by $\chi^{2}$ values. Both $\chi^{2}$ values and Dimensionless equilibrium parameter $\left(R_{L}\right)$ [28] are reflected in Table 4.

\subsubsection{Thermodynamic Studies}

Thermodynamic parameters viz. standard free energy change $\left(\Delta G^{0}\right)$, standard enthalpy change $\left(\Delta H^{\ominus}\right)$, standard entropy change $\left(\Delta S^{0}\right)$, activation energy $\left(E_{\mathrm{a}}\right)$, were calculated as follows. Considering the sorption distribution coefficient $K_{0}$, equation of free energy of sorption process, is given by

$$
\Delta G^{0}=-R T \ln K_{0}
$$

where $\Delta G^{0}$ is the standard free energy change $\left(\mathrm{kJ} \cdot \mathrm{mol}^{-1}\right), R$ is the universal gas constant $\left(8.314 \mathrm{~J} \cdot \mathrm{mol}^{-1} \cdot \mathrm{K}^{-1}\right)$ and $T$ is the temperature in Kelvin. As per the method proposed by Khan and Singh [29], the sorption distribution coefficient $K_{0}$ 

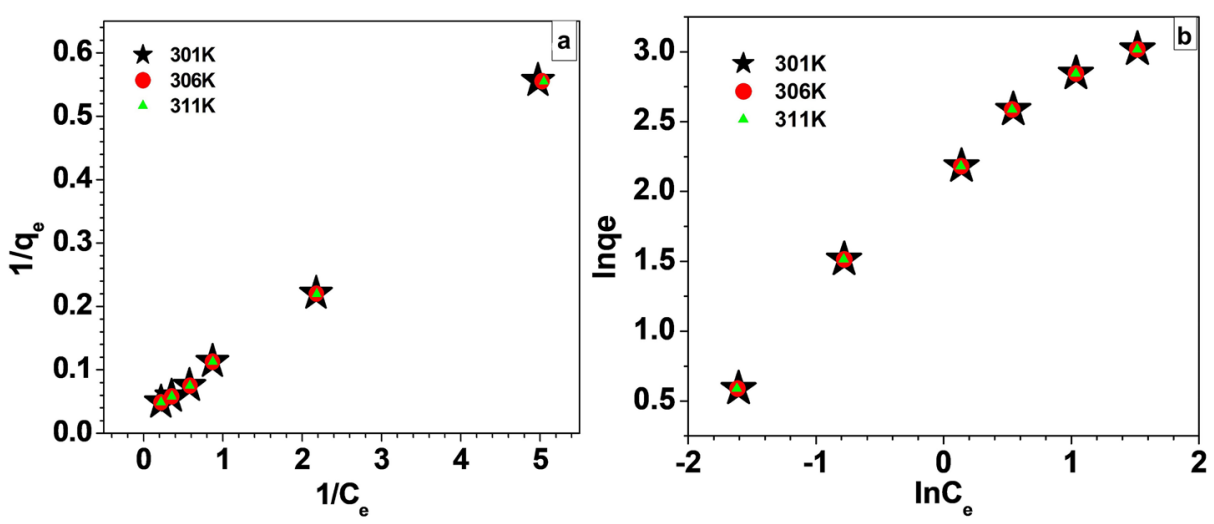

Figure 11. Langmuir isotherm of MCM-41 (a) and Freundlich isotherm of MCM-41 (b).

Table 3. A comparison of Langmuir and Freundlich isotherm parameters.

\begin{tabular}{ccccccccccc}
\hline Temp (K) & \multicolumn{3}{c}{ Langmuir isotherm parameters } & \multicolumn{5}{c}{ Freundlich isotherm parameters } \\
\hline & $\begin{array}{c}q_{m} \\
(\mathrm{mg} / \mathrm{g})\end{array}$ & $\begin{array}{c}b \\
(\mathrm{~L} / \mathrm{mg})\end{array}$ & $R^{2}$ & S.D. & $1 / n$ & $n$ & $\begin{array}{c}K_{f} \\
\left(\mathrm{mg}^{1-1 / n} \cdot \mathrm{L}^{1 / n} \cdot \mathrm{g}^{-1}\right)\end{array}$ & $R^{2}$ & S.D. \\
\hline 301 & 63.0517 & 0.1490 & 0.9974 & 0.01588 & 0.7856 & 1.2729 & 7.4568 & 0.9883 & 0.1577 \\
306 & 60.6060 & 0.1568 & 0.9977 & 0.0149 & 0.7839 & 1.2756 & 7.4837 & 0.9893 & 0.1573 \\
311 & 44.8229 & 0.2156 & 0.9976 & 0.0147 & 0.7785 & 1.30144 & 7.2365 & 0.9885 & 0.1568 \\
\hline
\end{tabular}

Table 4. The $R_{L}$ and chi-square values of MCM-41.

\begin{tabular}{ccccccccc}
\hline Temp. & \multicolumn{9}{c}{$R_{L}$ values } & \multicolumn{2}{c}{$\chi^{2}$ values for isotherms } \\
\hline$(\mathrm{K})$ & $2 \mathrm{mg} / \mathrm{L}$ & $5 \mathrm{mg} / \mathrm{L}$ & $10 \mathrm{mg} / \mathrm{L}$ & $15 \mathrm{mg} / \mathrm{L}$ & $20 \mathrm{mg} / \mathrm{L}$ & $25 \mathrm{mg} / \mathrm{L}$ & Langmuir & Freundlich \\
301 & 0.7703 & 0.5730 & 0.4015 & 0.3090 & 0.2512 & 0.2116 & 1.21959 & 1.13560 \\
306 & 0.7613 & 0.5605 & 0.31194 & 0.2983 & 0.2418 & 0.20306 & 1.11404 & 1.14985 \\
311 & 0.6987 & 0.4813 & 0.3169 & 0.2362 & 0.1883 & 0.1565 & 0.306092 & 1.15578 \\
\hline
\end{tabular}

for sorption reaction was determined from the slope of the plot $\ln \left(\frac{q_{e}}{C_{e}}\right)$ against $C_{e}$ at various temperatures and extrapolating to zero $C_{e}$. The sorption distribution coefficient may be expressed as

$$
\ln K_{0}=\frac{\Delta H^{0}}{R T}+\frac{\Delta S^{0}}{R}
$$

where $\Delta H^{\oplus}$ is standard enthalpy change $\left(\mathrm{kJ} \cdot \mathrm{mol}^{-1}\right)$ and $\Delta S^{0}$ is standard entropy change $\left(\mathrm{kJ} \cdot \mathrm{mol}^{-1} \cdot \mathrm{K}^{-1}\right)$. The values of $\Delta H^{\oplus l}$ and $\Delta S^{0}$ can be obtained from the slope and intercept of a plot of $\ln K_{0}$ against $\bar{T}$ respectively. The values of activation energy $\left(E_{a}\right)$ and sticking probability $(S)$ were calculated from the experimental data. These were calculated using a modified Arrhenius type equation related to surface coverage as expressed in Equation (12).

$$
S^{*}=(1-\theta) \exp -\left(\frac{E_{a}}{R T}\right)
$$


where, $\theta$ is surface coverage,

$$
\theta=\left(1-\frac{C_{e}}{C_{0}}\right)
$$

where, $C_{0}$ and $C_{e}$ are the initial and equilibrium fluoride concentrations respectively. The plot of $\ln (1-\theta)$ against $\frac{1}{T}$ will give a linear plot with intercept of $\ln S$ and slope of $\frac{E_{a}}{R}$. In the sorption process, temperature plays a major role as influencing factor, the sorption of mesoporous MCM-41 was monitored at three different temperatures 301,306 and $311 \mathrm{~K}$ under optimized conditions. The thermodynamic parameters viz. $\Delta G, \Delta H^{0}, \Delta S$ and $E_{a}$, were calculated with the help of Equations (9)-(11) and are presented in Table 5. The endothermic behaviour of adsorption is clearly indicated by +ve $\Delta H^{\ominus}$ value and -ve $\Delta G^{0}$ value indicates the spontaneous nature of the adsorption process. From the low value of $\Delta S^{0}$, it may be concluded that there is no marked change in entropy occurred during the adsorption process. However, the increase of randomness at the solid solution interface during adsorption may be predicted from $+\mathrm{ve} \Delta S^{0} . \Delta H^{\dagger}\left(2.3016 \mathrm{~kJ} \cdot \mathrm{mol}^{-1}\right)$ value indicates that the adsorption process is a physico-chemical adsorption process rather than a pure physical or chemical one, as heats of chemisorption generally fall into the range [30] [31] of $80-200 \mathrm{~kJ} \cdot \mathrm{mol}^{-1}$. The value of $S(0.10)$ indicates that adsorption mechanism does not follow purely chemisorption.

\subsubsection{Adsorption Kinetics}

In order to investigate the sorption mechanism of fluoride removal both Pseudo first and second-order kinetic models are used at different experimental conditions. Pseudo-first-order kinetic model is represented as

$$
\log \left(q_{e}-q_{t}\right)=\log q_{e}-\frac{K_{a d}}{2.303} t
$$

where $q_{t}$ is the amount of fluoride on the surface of the sorbent MCM-41 at time $t(\mathrm{mg} / \mathrm{g})$ and $K_{a d}$ is the equilibrium rate constant $\left(\mathrm{min}^{-1}\right)$. Figures 12(a)-(c) show the linear plots of pseudo-first-order for sorption of fluoride onto MCM-41 at 301 $\mathrm{K}, 306 \mathrm{~K}$ and $311 \mathrm{~K}$ respectively.

The most popular linear form of pseudo-second-order kinetic model is expressed as

$$
\frac{t}{q_{t}}=\frac{1}{h}+\frac{t}{q_{e}}
$$

Table 5. Thermodynamic parameters at three different temperatures for Fluoride.

\begin{tabular}{cccccc}
\hline \multicolumn{5}{c}{ Thermodynamic parameters } \\
\hline Temp. (K) & $\Delta G^{0}(\mathrm{~kJ} / \mathrm{mol})$ & $\Delta H^{0}(\mathrm{~kJ} / \mathrm{mol})$ & $\Delta S^{0}(\mathrm{~kJ} / \mathrm{molK})$ & $E_{a}(\mathrm{~kJ} / \mathrm{mol})$ & $S$ \\
\hline 301 & -0.5486 & 2.30164 & $9.4 \times 10^{-3}$ & 0.3462 & 0.1001 \\
306 & -0.5957 & & & & \\
311 & -0.64301 & & & \\
\hline
\end{tabular}


Table 6. Pseudo-second-order kinetic parameters of MCM-41.

\begin{tabular}{cccccc}
\hline \multirow{2}{*}{ Temp (K) } & $\begin{array}{c}\text { Conc } \\
(\mathrm{ml} / \mathrm{L})\end{array}$ & $\begin{array}{c}q_{e} \\
(\mathrm{mg} / \mathrm{g})\end{array}$ & $\begin{array}{c}k \\
(\mathrm{~g} / \mathrm{mg} \cdot \mathrm{min})\end{array}$ & $\begin{array}{c}h \\
(\mathrm{mg} / \mathrm{g} \cdot \mathrm{min})\end{array}$ & $R^{2}$ \\
\hline \multirow{3}{*}{301} & 2 & 0.8985 & 6.6151 & 5.3405 & 0.9999 \\
& 5 & 2.30185 & 0.8936 & 4.6805 & 0.9999 \\
& 10 & 4.4324 & 1.4460 & 301.4090 & 1 \\
& 15 & 5.2102 & 0.2720 & 0.7391 & 0.9848 \\
& 20 & 8.5410 & 1.6368 & 11.6959 & 0.999 \\
& 25 & 10.217 & 0.30172 & 29.9850 & 0.9998 \\
& 2 & 0.9084 & 6.5694 & 5.4215 & 0.9999 \\
& 5 & 2.976 & 9.7745 & 8.6580 & 1 \\
& 10 & 6.0606 & 0.1143 & 19.6618 & 0.9999 \\
& 15 & 7.9987 & 0.1248 & 7.9865 & 0.9997 \\
& 20 & 9.6116 & 0.4085 & 37.7358 & 0.9999 \\
& 25 & 10.860 & 0.1501 & 17.7022 & 1 \\
& 25 & 0.9115 & 7.3018 & 6.0668 & 1 \\
& 25 & 2.9882 & 3.650 & 32.5945 & 0.9999 \\
& 5 & 5.744 & 0.1765 & 5.8251 & 0.9996 \\
& 10 & 7.8143 & 0.2539 & 15.5063 & 0.9999 \\
& 15 & 10.454 & 0.0719 & 7.8554 & 0.9994 \\
& 20 & 0.0598 & 8.1960 & 0.9998 \\
\hline
\end{tabular}
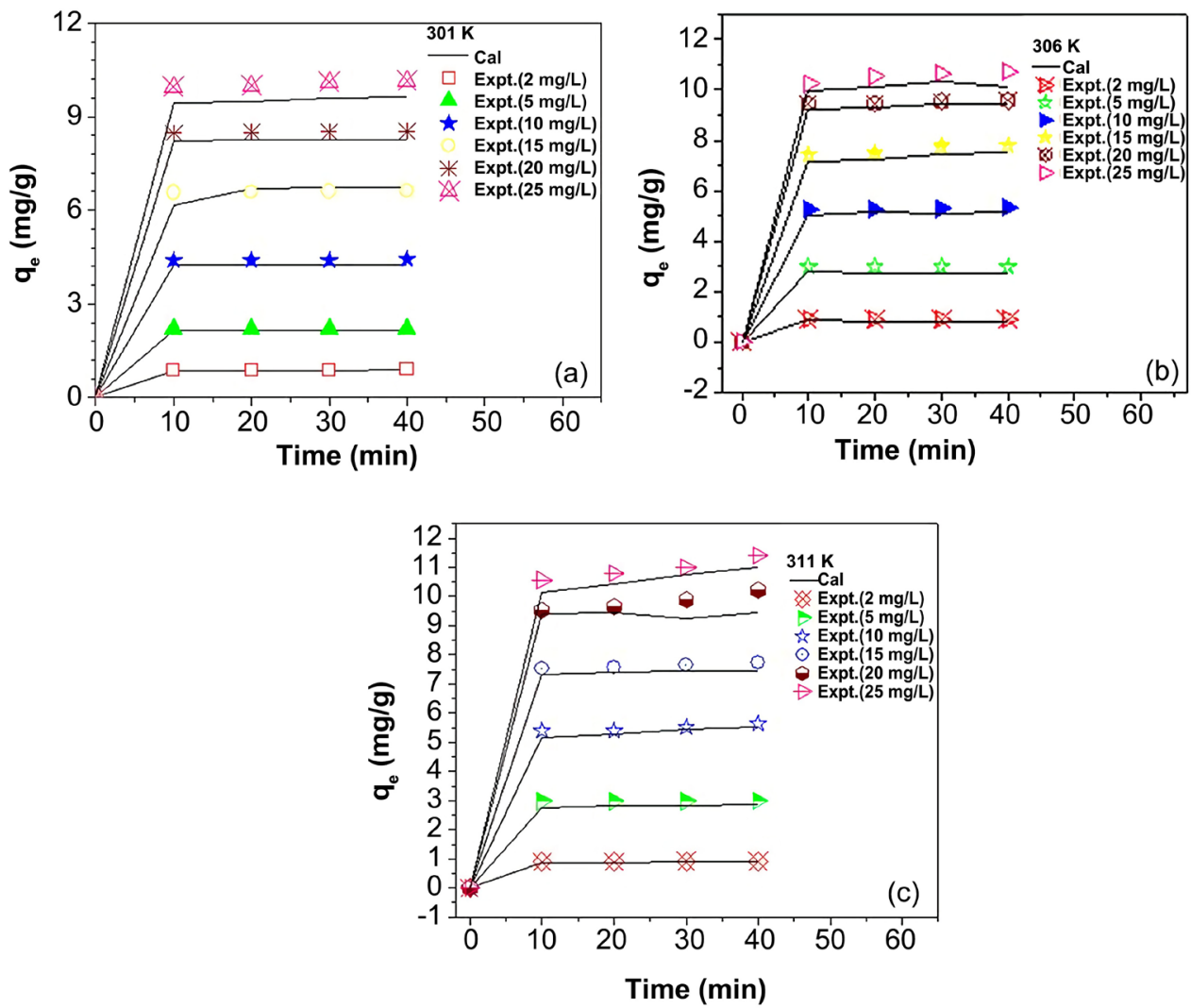

Figure 12. Pseudo-first-order plot for fluoride removal at 301, 306 and $311 \mathrm{~K}$. 
where, $q_{t}=q_{e}^{2} k t /\left(1+q_{t} k t\right)$, the amount of fluoride on the surface of the meso-

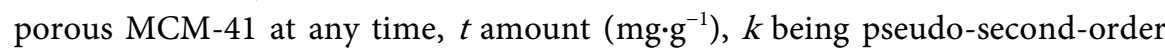
rate constant $\left(\mathrm{gm} \cdot \mathrm{g}^{-1} \cdot \mathrm{min}^{-1}\right)$, is the amount of fluoride sorbed at equilibrium $(\mathrm{mg} / \mathrm{g})$ and the initial sorption rate, $h=k q_{e}^{2}\left(\mathrm{mg} \cdot \mathrm{g}^{-1} \cdot \mathrm{min}^{-1}\right)$. The value of $q_{e} k$ and $h$ of the pseudo-second-order equation were obtained experimentally for fluoride sorption at different temperatures viz. 301, 306 and $311 \mathrm{~K}$. The plot of $t$ vs $\frac{t}{q_{t}}$ gives a straight line with higher correlation coefficient $R^{2}$ values. This is higher than that observed pseudo-first-order model indicating the applicability $q_{e}$ of the pseudo-second-order model. Figures 13(a)-(c), depict the linear plot of pseudo second order for sorption of fluoride on MCM-41 at 301, 306 and $311 \mathrm{~K}$ respectively. Overall results revealed the value of $q_{e}$ is increasing with the increase of initial Fluoride concentration and temperature. These values are reflected in Table 6.

\subsubsection{RSM Approach for the Optimization of Fluoride Adsorption}

The actual and predicted removals (\%) of fluoride on MCM-41 are found very close to each other. It is calculated by applying BBD techniques. The details of RSM approach for the optimization of fluoride adsorption on MCM-41 is also described. The suitability of regression model for fluoride adsorption on MCM-41 is suggested from the results, observed in Table 7. It is revealed that the predicted values are quite close to the experimental one. It is clear from the Table 8 that $\mathrm{p}$-value of all linear terms; all square term, and $\mathrm{pH}^{\star} \mathrm{Conc}$. terms are less than 0.05 .
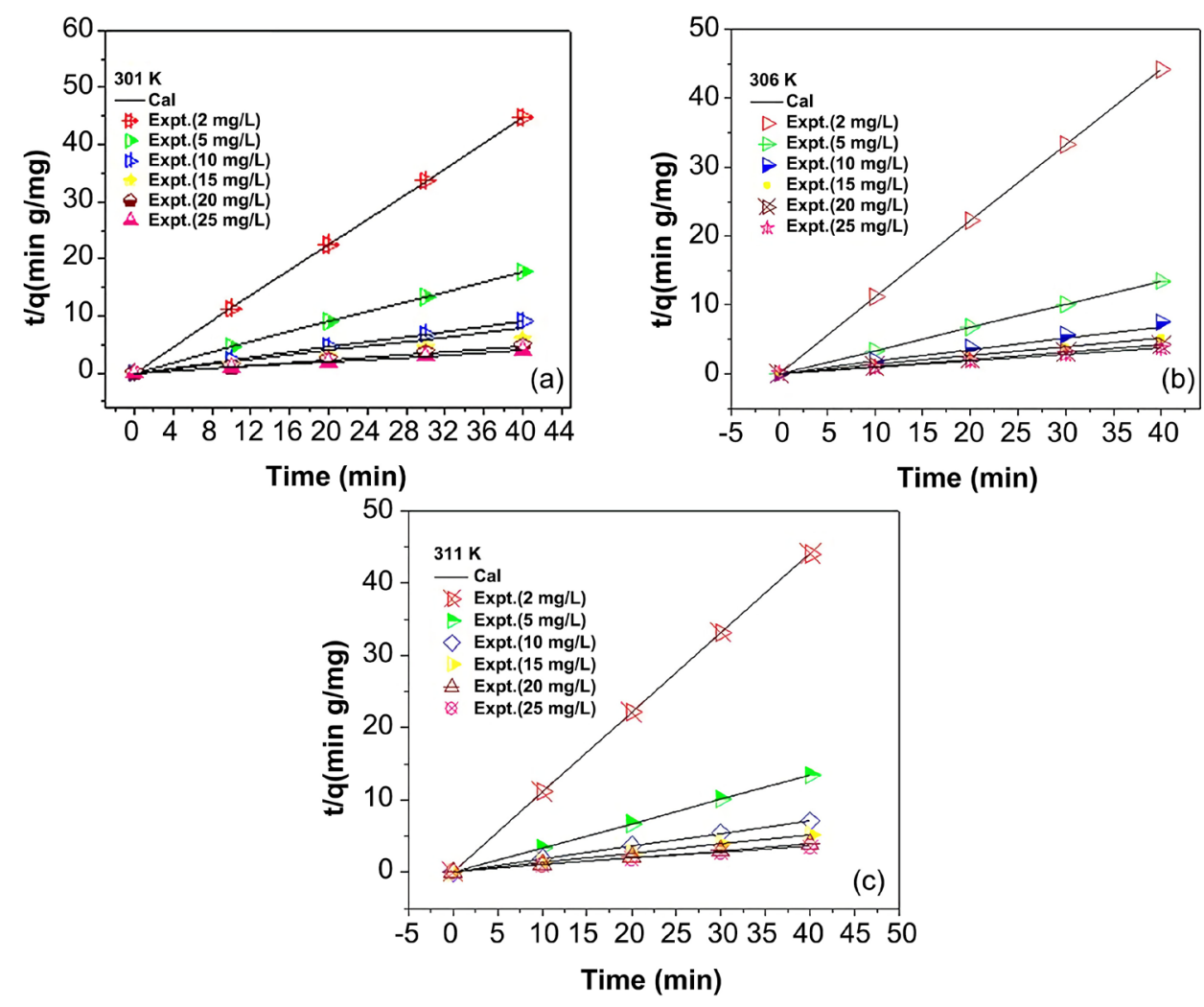

Figure 13. Observed pseudo-second-order plot at $301 \mathrm{~K}, 306 \mathrm{~K}$ and 311. 
Table 7. Response surface regression: Removal (\%) vs $\mathrm{pH}$, conc. (mg/L), contact time (min).

\begin{tabular}{ccccc}
\hline Term & Coef & SE Coef & $\mathrm{T}$ & $\mathrm{P}$ \\
\hline Constant & 78.1667 & 0.9072 & 86.166 & 0.000 \\
$\mathrm{pH}$ & 2.2125 & 0.5555 & 3.983 & 0.011 \\
Conc. $(\mathrm{mg} / \mathrm{L})$ & -7.0875 & 0.5555 & -12.758 & 0.000 \\
$\mathrm{CT}(\mathrm{min})$ & 4.2000 & 0.5555 & 7.560 & 0.001 \\
$\mathrm{pH}{ }^{\star} \mathrm{pH}$ & -49.9833 & 0.8177 & -61.126 & 0.000 \\
Conc. $(\mathrm{mg} / \mathrm{L})^{*} \mathrm{Conc} .(\mathrm{mg} / \mathrm{L})$ & 7.3667 & 0.8177 & 9.009 & 0.000 \\
$\mathrm{CT}(\mathrm{min})^{*} \mathrm{CT}(\mathrm{min})$ & -11.6583 & 0.8177 & -14.257 & 0.000 \\
$\mathrm{pH} \mathrm{Conc}^{*}(\mathrm{mg} / \mathrm{L})$ & 5.9000 & 0.7856 & 7.510 & 0.001 \\
$\mathrm{pH}{ }^{*} \mathrm{CT}(\mathrm{min})$ & 0.6250 & 0.7856 & 0.796 & 0.462 \\
Conc. $(\mathrm{mg} / \mathrm{L})^{*} \mathrm{CT}(\mathrm{min})$ & 1.6750 & 0.7856 & 2.132 & 0.086 \\
\hline
\end{tabular}

Table 8. Analysis of variance for the removal (\%) of fluoride.

\begin{tabular}{|c|c|c|c|c|c|c|}
\hline Source & DF & Seq SS & Adj SS & Adj MS & $\mathrm{F}$ & $\mathrm{P}$ \\
\hline Regression & 9 & 10702.7 & 10702.7 & 1189.19 & 481.68 & 0.000 \\
\hline Linear & 3 & 582.1 & 582.1 & 194.05 & 78.60 & 0.000 \\
\hline $\mathrm{pH}$ & 1 & 39.2 & 39.2 & 39.16 & 15.86 & 0.011 \\
\hline Conc. & 1 & 401.9 & 401.9 & 401.86 & 162.77 & 0.000 \\
\hline CT & 1 & 141.1 & 141.1 & 141.12 & 57.16 & 0.001 \\
\hline Square & 3 & 9968.5 & 9968.5 & 3322.84 & 1345.92 & 0.000 \\
\hline $\mathrm{pH}^{*} \mathrm{pH}$ & 1 & 9213.1 & 9224.6 & 9224.62 & 3736.43 & 0.000 \\
\hline Conc. ${ }^{\star C o n c}$. & 1 & 253.6 & 200.4 & 200.37 & 81.16 & 0.000 \\
\hline $\mathrm{CT}^{*} \mathrm{CT}$ & 1 & 501.8 & 501.8 & 501.85 & 203.27 & 0.000 \\
\hline Interaction & 3 & 152.0 & 152.0 & 50.67 & 20.53 & 0.003 \\
\hline $\mathrm{pH}^{\star}$ Conc. & 1 & 139.2 & 139.2 & 139.24 & 56.40 & 0.001 \\
\hline $\mathrm{pH}^{*} \mathrm{CT}$ & 1 & 1.6 & 1.6 & 1.56 & 0.63 & 0.462 \\
\hline Conc. ${ }^{\star} \mathrm{CT}$ & 1 & 11.2 & 11.2 & 11.22 & 4.55 & 0.086 \\
\hline Residual Error & 5 & 12.3 & 12.3 & 2.47 & & \\
\hline Lack-of-Fit & 3 & 11.2 & 11.2 & 3.73 & 6.39 & 0.138 \\
\hline Pure Error & 2 & 1.2 & 1.2 & 0.58 & & \\
\hline Total & 14 & $10,715.0$ & & & & \\
\hline
\end{tabular}

3.3.9. Interactive Effects of Different Parameters on Fluoride Adsorption In this study, the effects of the predominant variables (pH and Conc.) on the response (\% removal) are depicted in Figure 14. Response model plot is depicted in Figure 15, which is very supportive to predict the optimum values for the de- 
sired response. The relation between various adsorption parameters and response can be explained by the examination of contour plots as a function of two factors by holding the other factors at central level. The strength of a particular variable is appraised by the magnitude of the coefficient and the nature of the variable is indicated by the subtraction or addition sign in the equation [32].

\subsubsection{Interpretation of Response Model Curve}

Model suggested that $77.88 \%$ of fluoride removal from aqueous solution should be achieved at conditions i.e., at Conc. (10 mg/L), pH (6.3) and CT (120 min). The experiments were also conducted at the aforementioned condition and found more than $75 \%$ removal efficiency. The experimental and theoretical results closely match with each other. The percentage error difference between the experimental and predicted value is very low, which validity the findings of response model curve. It also indicates that the proposed model is adequate for obtaining most favorable value in the range of the studied parameters.
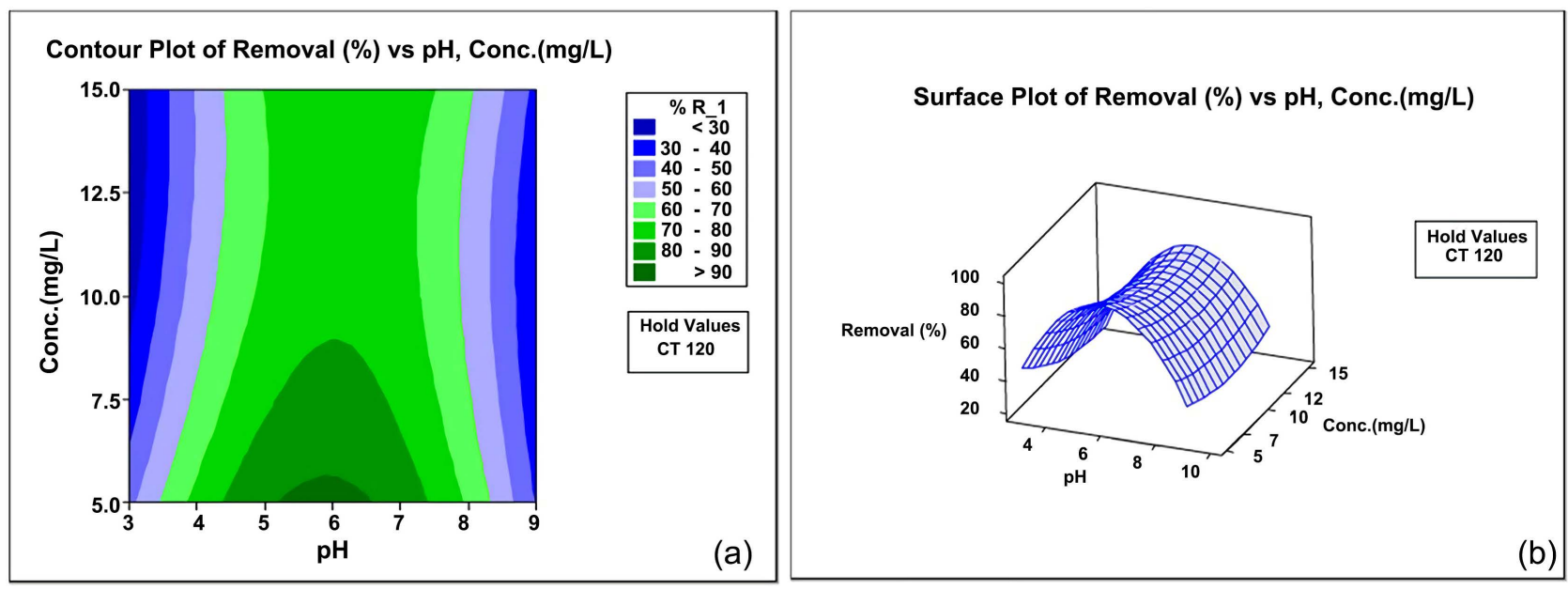

Figure 14. (a) Contour plot at $120 \mathrm{~min}$ and (b) Surface plot at $120 \mathrm{~min}$.

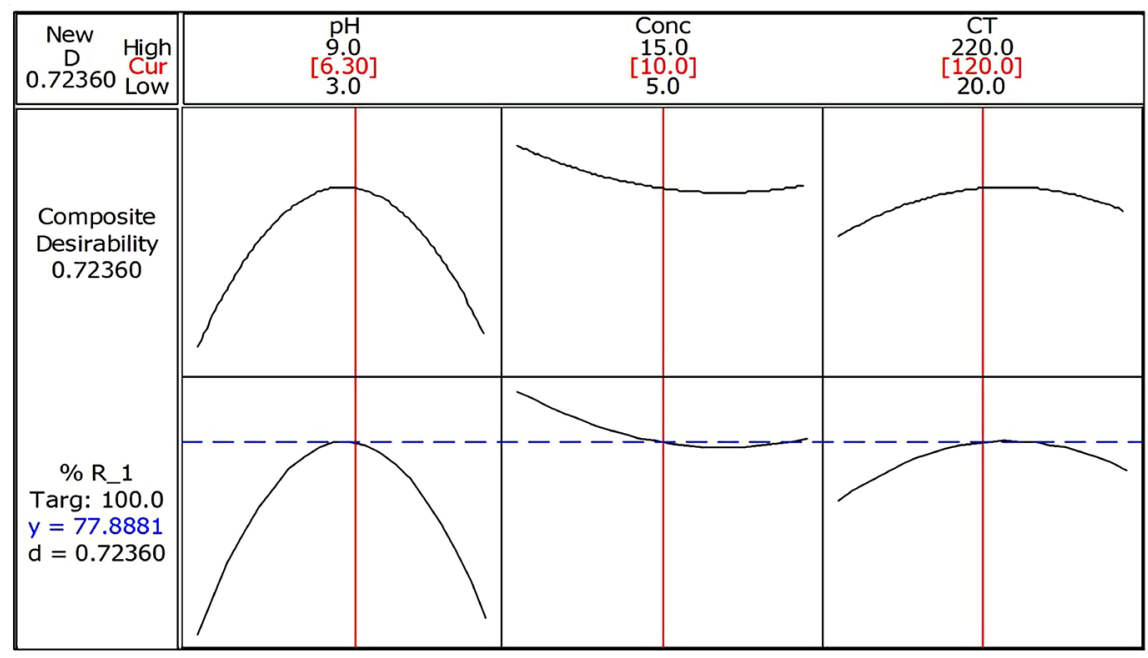

Figure 15. Response model plot for fluoride removal. 


\section{Conclusion}

Mesoporous MCM-41 has been found to be potential adsorbents for fluoride removal from water. The fluoride sorption onto MCM-41 materials is significantly influenced by $\mathrm{pH}$ of the medium. The maximum sorption capacity of the sorbent is calculated as $63.05 \mathrm{mg} \cdot \mathrm{g}^{-1}$ at $301 \mathrm{~K}$ and best at $\mathrm{pH}$ 6.3. The +ve $\Delta \mathrm{H}^{0}$ $\left(2.30 \mathrm{KJ} \cdot \mathrm{mol}^{-1}\right)$ and -ve $\Delta \mathrm{G}^{0}$ values reveal the endothermic and spontaneous nature of the adsorption process respectively. The adsorption process is a physico-chemical adsorption process rather than a pure physical or chemical one. The randomness increased at the solid-solution interface during adsorption, it is indicated from $+v e \Delta S^{0}$ value. Equilibrium sorption data shows a better fit to Langmuir isotherm than Freundlich one, indicating monolayer adsorption on the heterogeneous surface of MCM-41. Kinetics shows that adsorption of fluoride onto MCM-41 follows pseudo-second-order kinetics. RSM pointed out optimum percentage removal at $\mathrm{pH}=6.3$, initial concentration $=10 \mathrm{mg} \cdot \mathrm{L}^{-1}$ and contact time $=120$ min with $77.88 \%$ of fluoride removal from aqueous solution. The experiments revealed more than $75 \%$ fluoride removal was achieved at the same environmental conditions. Confirmation experiments' results depicted harmony of experimental values with predicted values. The analysis obviously demonstrated that the $\mathrm{BBD}$ design is one of the suitable techniques to enhance the best working conditions to determine the fluoride removal from the aqueous solution with minimum number of experiments. $\mathrm{pH}$, initial concentration and contact time all factors were significant in removal of fluoride from the aqueous solution.

\section{Acknowledgements}

The authors are thankful to DRDO, Headquarters, New Delhi, for providing financial grant. Authors acknowledge Dr. Durlab Saikia, Gauhati University for TGA analysis of MCM-41.

\section{Conflicts of Interest}

The authors declare no conflicts of interest regarding the publication of this paper.

\section{References}

[1] Susheela, A.K. (1919) Fluorosis Management Programme in India. Current Science, 77, 1250-1256.

[2] World Health Organization (2008) Guidelines for Drinking-Water Quality. Vol. 1, 3rd Edition.

[3] Chakraborti, D., Chanda, C.R., Samanta, G., Chowdhury, U.K., Mukherjee, S.C. and Pal, A.B. (2000) Fluorosis in Assam, India. Current Science, 78, 1421-1423.

[4] Goswami, A., Raul, P.K. and Purkait, M.K. (2012) Arsenic Adsorption Using Copper (II) Oxide Nanoparticles. Chemical Engineering Research and Design, 90, 1387-1396. https://doi.org/10.1016/j.cherd.2011.12.006 
[5] Thakur, S., Das, G., Raul, P.K. and Karak, N. (2013) Green One-Step Approach to Prepare Sulfur/Reduced Graphene Oxide Nanohybrid for Effective Mercury Ions Removal. Journal of Physical Chemistry C, 117, 7636-7642. https://doi.org/10.1021/jp400221k

[6] Antonelli, D.M. and Ying, J.Y. (1996) Synthesis and Characterization of Hexagonally Packed Mesoporous Tantalum Oxide Molecular Sieves. Chemistry of Materials, 8, 874. https://doi.org/10.1021/cm9504697

[7] Nalwa, H.S. (2004) Encyclopedia of Nanoscience and Nanotechnology. American Scientific Publishers, Los Angeles, 1-10.

[8] Sayari, A., Jaroniec, M. and Pinnavaia, T.J. (2000) Nanoporous Materials II (Studies in Surface Science and Catalysis, Volume 129). Elsevier, Amsterdam. https://doi.org/10.1016/S0167-2991(00)80186-X

[9] Serrano, D.P., Aguado, J. and Escola, J.M. (2000) Catalytic Cracking of a Polyolefin Mixture over Different Acid Solid Catalysts. Industrial \& Engineering Chemistry Research, 39, 1177. https://doi.org/10.1021/ie9906363

[10] Onyango, M.S., Masukume, M., Ochieng, A. and Otieno, F. (2010) Functionalised Natural Zeolite and Its Potential for Treating Drinking Water Containing Excess amount of Nitrate. Water $S A, 36,655$. https://doi.org/10.4314/wsa.v36i5.61999

[11] Tuel, A. and Gontier, S. (1996) Synthesis and Characterization of Trivalent Metal Containing Mesoporous Silicas Obtained by a Neutral Templating Route. Chemistry of Materials, 8, 114-122. https://doi.org/10.1021/cm950276j

[12] Abdelwahab, El. Nemr, A., El. Sikaily, A. and Khaled, A. (2005) Use of Rice Husk for Adsorption of Direct Dyes from Aqueous Solution: A Case Study of Direct F. Scarlet, Egyptian. Journal of Aquatic Research, 31, 1-11.

[13] Caponetti, E., Pedone, L., Saladino, M.L., Martino, D.C. and Nasillo, G. (2010) MCM-41-CdS Nanoparticle Composite Material: Preparation and Characterization. Microporous and Mesoporous Materials, 128, 101-107. https://doi.org/10.1016/j.micromeso.2009.08.010

[14] Huo, Q., Margolese, D.I. and Stucky, G.D. (1996) Surfactant Control of Phases in the Synthesis of Mesoporous Silica-Based Materials. Chemistry of Materials, 8, 1147-1160. https://doi.org/10.1021/cm960137h

[15] Diaz-Nava, C., Olguin, M.T. and Solache-Rios, M. (2007) Water Defluoridation by Mexican Heulandite-Clinoptilolite. Separation Science and Technology, 37, 3109-3128. https://doi.org/10.1081/SS-120005662

[16] Fryxell, G.E., Liu, J., Hauser, T.A., Nie, Z., Ferris, K.F., Mattigod, S., Gong, M. and Hallen, R.T. (1999) Design and Synthesis of Selective Mesoporous Anion Traps. Chemistry of Materials, 11, 2148-2154. https://doi.org/10.1021/cm990104c

[17] Sundaram, C.S., Viswanathan, N. and Meenakshi, S. (2008) Defluoridation Chemistry of Synthetic Hydroxyapatite at Nano Scale: Equilibrium and Kinetic Studies. Journal of Hazarous Materials, 155, 206-215. https://doi.org/10.1016/j.jhazmat.2007.11.048

[18] Raichur, A.M. and Basu, M.J. (2001) Adsorption of Fluoride onto Mixed Rare Earth Oxides. Separation and Purification Technology, 24, 121. https://doi.org/10.1016/S1383-5866(00)00219-7

[19] Yadav, A.K., Kaushik, C.P., Haritash, A.K., Singh, B., Raghuvanshi, S.P. and Kansal, A. (2007) Determination of Exposure and Probable Ingestion of Fluoride through Tea, Toothpaste, Tobacco and Pan Masala. Journal of Hazardous Materials, 142, 77-80. https://doi.org/10.1016/j.jhazmat.2006.07.051 
[20] Prasad, M., Saxena, S. and Amritphale, S.S. (2002) Adsorption Models for Sorption of Lead and Zinc on Francolite Mineral. Industrial\& Engineering Chemistry Research, 41, 105-111. https://doi.org/10.1021/ie0102302

[21] Meenakshi, S., Sundaram, C.S. and Sukumar, R. (2009) Fluoride Sorption by Nano-Hydroxyapatite/Chitin Composite. Journal of Hazardous Materials, 172, 147-151. https://doi.org/10.1016/j.jhazmat.2009.06.152

[22] Hadi, M., Samarghandi, M.R. and Mckay, G. (2010) Equilibrium Two-Parameter Isotherms of Acid Dyes Sorption by Activated Carbons: Study of Residual Errors. Chemical Engineering Journal, 160, 408. https://doi.org/10.1016/j.cej.2010.03.016

[23] Khan, A. and Singh, R.P. (1987) Adsorption Thermodynamics of Carbofuran on $\mathrm{Sn}(\mathrm{IV})$ Arsenosilicate in $\mathrm{H}^{+}, \mathrm{Na}^{+}$and $\mathrm{Ca}^{2+}$ Forms. Colloids and Surfaces A: Physicochemical and Engineering Aspects, 24, 306. https://doi.org/10.1016/0166-6622(87)80259-7

[24] Xiong, C.H., Yao, C.P., Wang, L. and Ke, J.J. (2009) Adsorption Behaviour of Cd(II) from Aqueous Solution onto Gel-Type Weak Acid Resin. Hydrometallurgy, 98, 318. https://doi.org/10.1016/j.hydromet.2009.05.008

[25] Zeng, L. (2004) Arsenic Adsorption from Aqueous Solutions on an Fe(III)-Si Binary Oxide Adsorbent. Water Quality Research Journal Canada, 39, 267-275. https://doi.org/10.2166/wqri.2004.037

[26] Raul, P.K., Senapati, S., Sahoo, A.K., Umlong, I.M., Devi, R.R., Thakur, A.J. and Veer, V. (2014) Cu Onanorods: A Potential and Efficient Adsorbent in Water Purification. RSC Advances, 4, 40580-40587. https://doi.org/10.1039/C4RA04619F

[27] Horsfall, M. and Spiff, I.A. (2005) Effects of Temperature on the Sorption of $\mathrm{Pb}^{2+}$ and $\mathrm{Cd}^{2+}$ from Aqueous Solution by Caladium Bicolor (Wild Cocoyam) Biomass. Electronic Journal of Biotechnology, 8, 1010-1013. https://doi.org/10.2225/vol8-issue2-fulltext-4

[28] Lagergren, S. (1898) Zur Theorie der sogenannten Adsorption gelöster Stoffe. K. Sven Vetenskapsakad. Handl 24, 1-39.

[29] Ho, Y.S. (2006) Second-Order Kinetic Model for the Sorption of Cadmium onto Tree Fern: A Comparison of Linear and Non-Linear Methods. Water Research, 40, 119-125. https://doi.org/10.1016/j.watres.2005.10.040

[30] Ngah, W.S.W., Fatinathan, S. and Yosop, N.A. (2011) Isotherm and Kinetic Studies on the Adsorption of Humic Acid onto Chitosan- $\mathrm{H}_{2} \mathrm{SO}_{4}$ Beads. Desalination, 272, 293-300. https://doi.org/10.1016/j.desal.2011.01.024

[31] Boparai, H.K., Joseph, M. and Carroll, D.M.O. (2011) Kinetics and Thermodynamics of Cadmium Ion Removal by Adsorption onto Nano Zero Valent Iron Particles. Journal of Hazardous Materials, 186, 458-465. https://doi.org/10.1016/j.jhazmat.2010.11.029

[32] Sarkar, M. and Majumdar, P. (2011) Application of Response Surface Methodology for Optimization of Heavy Metal Biosorption Using Surfactant Modified Chitosan Bead. Chemical Engineering Journal, 175, 376-387.

https://doi.org/10.1016/j.cej.2011.09.125 